International Journal of Advanced Trends in Computer Science and Engineering

Available Online at http://www.warse.org/IJATCSE/static/pdf/file/ijatcse136922020.pdf

https://doi.org/10.30534/ijatcse/2020/136922020

\title{
Wave Analogies in The Quantitative Interpretation of Potential Fields
}

\author{
Igor Borisovich Movchan, Alexandra Anatol'evna Yakovleva \\ Saint-Petersburg Mining University, Russia
}

\begin{abstract}
Traditionally, wave processes in geology refer to the seismological phenomena or seismic exploration. Wave dynamics are manifested directly in the structure of the rock massif and are objectively related to the temporal regularity of tectonic-magmatic activations, transgressions, and regressions, to opening and closing of ancient oceans, and the spatial distribution of these processes. Based on wave analogies between the non-equilibrium hydrodynamics and the geological environments, a method has been proposed for quasi-wave representation of the gravity field converted to the geological half-space. The algorithmic novelty of the method consists in a combination of narrow-band self-adjusting filtering of a spatial signal, quantitative spectral estimates of the anomaly-forming source depth, and adequate graphic visualizations of the resulting structural cross-sections. The novelty for geophysics is in high correlations of the structural forms revealed by interpretation of the seismic wave cross-sections and, independently, the gravity field specified along the profile.
\end{abstract}

Key words: Wave analogies, inverse problem, potential field, gravity field, inverse problem, parametric section, Barents plate, Demidov aulacogen.

\section{INTRODUCTION}

The method for solving the inverse problem described in the article belongs to analytic continuation based on spectral estimates. Based on the classical works $[1,2]$, it may be argued that the amplitude-frequency composition of the potential fields contains the averaged information about the structure and the material composition of the geological environment. Unlike the methods of deterministic selection and deconvolution used for interpreting individual anomalies, spectral estimates imply taking significant samples that describe the anomalies sequence. Restricting themselves to the consideration of the two-dimensional problem, the authors believe that the spatial series of the field values specified along the profile that intersects heterogeneous tectonic structures is not stationary. Therefore, the linear filtering methods cannot be applied to the analytic continuation of the field with the use of the Fourier transformation. The solution to this problem seems to lie in compiling the elements of the deconvolution method and the method of analytical continuation: the spectral field assessment must be valid within the pattern sliding along the sample profile. Moreover, the dimensions of the pattern are determined by the minimum and the maximum depths of the anomaly-forming source.

The potential field analytically continued into the lower half-space is traditionally represented as an isoline map that describes the distribution of a reduced field or an effective physical parameter of the environment (density, magnetization, resistance) over the cross-section. An ambiguity of the ratios between the gradient zones of such a map and the tectonic (stratigraphic) boundaries and between the anomalies of the map and the synforms and antiforms is known. Therefore, the above representation of the analytically extended field is inadequately perceived by geologists. Along with the drilling data, the main materials used by them for building a geological cross-section are wave seismic cross-sections. Bearing this in mind, it is necessary to create a method for interpreting the results of the cheaper geophysical monitoring, which would provide a structural image of the geological environment that would be comparable with the structural image taken from the seismic cross-sections.

Any mathematical description of a geological cross-section, moreover, a description based on indirect traits, such as the potential fields observed on the daylight surface, is possible with a certain degree of approximation. Given these approximations, it is incorrect to assert a priori that the suggested method applies to any potential fields in any geodynamical setup. Thus, it should be noted that this article is a result of studying the deep structure of the Earth's crust using the system of regional geotransects [3, 4]. The method tested this way was used for the quantitative interpretation of the gravity field along the AP-1 profile (the Northern slope of the Baltic shield - the South-West side of the Barents' shelf plate) for three reasons:

1. the high exploration degree of the cross-section by the system of wells;

2. the presence of a deep (down to $40 \mathrm{~km}$ ) seismic cross-section (Fig. 2); and the intersection of the profile with heterogeneous and heterochronous geoblocks (Fig. 1). 


\section{METHODS: SUBSTANTIATION OF THE RECONSTRUCTION MODEL}

The used spectral recalculations of the gravity field as a spatial signal suggest a priori the presence of the components with regular grid steps between the extrema (the deterministic spatial periodicity) in the structure of this field. The structure of the gravity field itself is determined by the distribution of the density inhomogeneities in the geological half-space. Thus, the presence of spatial periodicity in the structure of the gravity field automatically assumes the existence of the spatial periodicity in the distribution of the mentioned density inhomogeneities. A particularity of this distribution is the absence of complete isostatic compensation, i.e., the geological environment is non-equilibrium in terms of density. As follows from trivial physical concepts, the appearance of spatially periodic structures in a nonpoint system taken out of equilibrium is unambiguously associated with the wave formation (by analogy with a hydrodynamic system). According to the work of J. Turner [5], the wavelength in a non-equilibrium hydrodynamic system with wave disturbances depends on the depth: the greater the depth is, the greater the wavelength is. An analogy may be drawn between the geological and the hydrodynamic environments since both lithological and petrographic formations in the conditions of the loads acting on the geological scale (tens and hundreds of million years) behave as plastic substances or as viscous liquids. If any sufficiently long geological cross-section is considered (Fig. 2), it can be noted that the stratification planes of formations show spatial periodicity in their relief, and with increasing the depth, this spatial period increases [6]. Summarizing, one can see the correctness of representing a structural geological cross-section as a wave assembly (internal impounded gravitational waves, O. V. Petrov [7]). Theoretically, it can be restored by any geophysical field [8-10]. However, wave reconstructions can only be correct for the gravity field, since the distribution of density anomalies in a geological environment, unlike that of, e.g., magnetization or polarizability anomalies, is continuous everywhere except for the daylight surface.

The idea of wave representation of the structure of a geological cross-section was tested on the example of the interpretation of the gravity field in the Bouguer anomaly defined along the AP-1 deep seismic profile. It stretches from the northern slope of the Baltic anticlise to the South Barents' depression (Fig. 1). The initial geological cross-section considered as the reference in interpreting the reconstructions by the gravity field was based on seismic materials: the interpretation of the sedimentary cover structures was based on the data of reflection seismic survey (RflSS) with refined velocity properties of the terrigenous deposits according to the data of refraction seismic survey (RfrSS), while in the reconstructions on the basement, the significance of these seismic methods was inverse. The lowest structural boundary traced laterally in the cross-section was the Moho discontinuity located at the depths in the range between 35 and $40 \mathrm{~km}$.

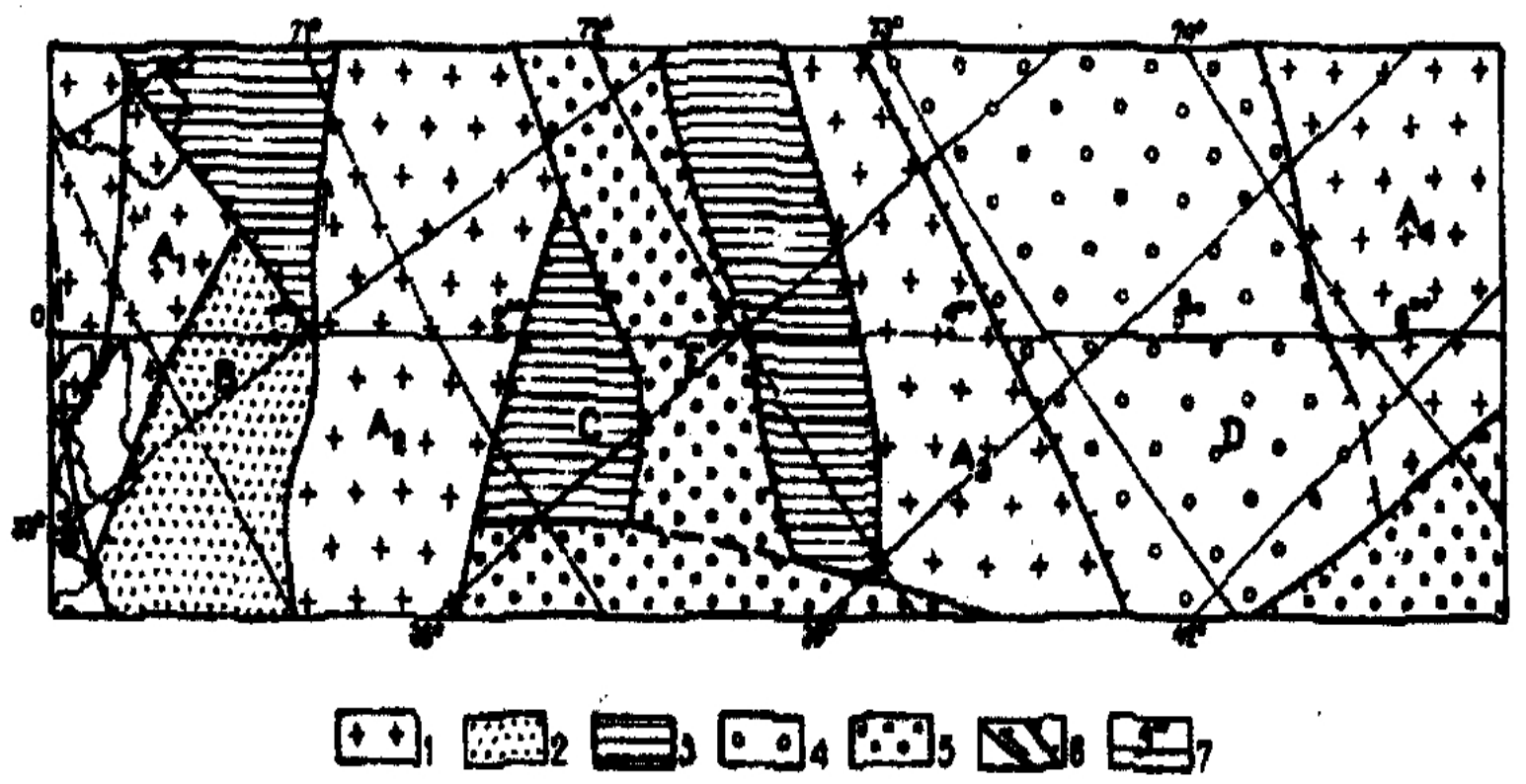

Figure 1: Arrangement of the tectonic structures

along the AP-1 regional profile: 1 - blocks of the Karelian basement:

$\mathrm{A}_{1}$ — the Northern slope of the Baltic shield partially overlaid by the Riphean formations, $\mathrm{A}_{2}$ - the North-Murmansk embedded inlier, $\mathrm{A}_{3}$ - the Fedynsky embedded inlier; $\mathrm{A}_{4}$ - the Fersman embedded inlier; 2 - the Riphean rifts: B — the East-Varanger rift; 3 - the Caledonian rifts: $\mathrm{C}$ - the West-Kola rift; 4 — the Middle Paleozoic aulacogens: D — the Demidov aulacogen; 5 - the Late Paleozoic - Triassic rifts: E — the Varanger graben; 6 - the regional faults and shifts; 7 - the line of the geotraverse. 
With that, its minimum occurrence depth corresponded to that of the Southern side of the Demidov aulacogen, and the maximum occurrence depth - to the shelf continuation of the Baltic shield structures. The following are considered paradoxical: the surface $\mathrm{M}$ elevation to $35 \mathrm{~km}$ under the North-Murmansk embedded inlier of the Archean basement and the high-amplitude surface $\mathrm{M}$ depression under the Northern wing of the Demidov aulacogen (Fig. 2). The paradox consists in the absence of explicit compliance with the isostatic compensation principle, or, in the terms introduced, in the absence of conformity of the roof and base displacements of the layer that is non-equilibrium in terms of density. The above-lying Conrad discontinuity inside the consolidated crust repeats all the main landforms of the $\mathrm{M}$ surface with the variations of the lower crust thickness in a relatively narrow range of $11-13 \mathrm{~km}$. Due to the rift-induced processing of the crust, the K surface cannot be traced within the West Kola depression. The upper layer of the consolidated crust, also called the granite layer, with the thickness of $10-$ $24 \mathrm{~km}$ can be traced everywhere along the section. The minimum thicknesses correspond to the Riphean depression in the area of the Kola-Kolguyev monocline and the Demidov aulacogen. The maximum thicknesses of the granite layer are found within the shelf extension of the Baltic shield. According to the data of the seismic survey, the overlying crystalline basement consists of two acoustic layers. The lower layer with the refractor velocity of $6,300 \mathrm{~m} / \mathrm{s}$ has a roof that lies at an average depth of $10 \mathrm{~km}$ and is associated with the formation of Archean gneisses. The overlying metamorphic series with an average thickness of about $8 \mathrm{~km}$ is identified as the Lower-Proterozoic Pechenga series. The shelf area where the Lower Proterozoic series is spread is believed to belong to the large palaeodepression adjacent to the Murmansk Archean block from the South, and the similar ledge of the ancient North-Murmansk basement from the North. The seismic horizon that overlays the roof of the crystalline basement substantially varies the depth of its roof occurrence along the profile from 0 to $12 \mathrm{~km}$ and is indirectly dated as Riphean by analogy to the Rybachinskaya series. To interpret the nature of the Riphean series, the Khain's tectonic model of the incompleteness of the geosynclinal conditions and their gradual change to the platform conditions is used. In the terrigenous formations, three terrestrial-structural complexes that lie unconformably on the Riphean deposits are identified. Of these, the lower one, which has a variegated material composition, dates back to the Upper Cambrian, Ordovician, and to a significant part of the Silurian periods (caledonides). The middle layer, which is mainly terrigenous, dates back to the Upper Silurian and the carbonate carboniferous Lower Permian series (early hercynides). The upper layer of the sedimentary cover is composed of the Upper Permian, Triassic, Jurassic, and Lower Cretaceous terrigenous formations.

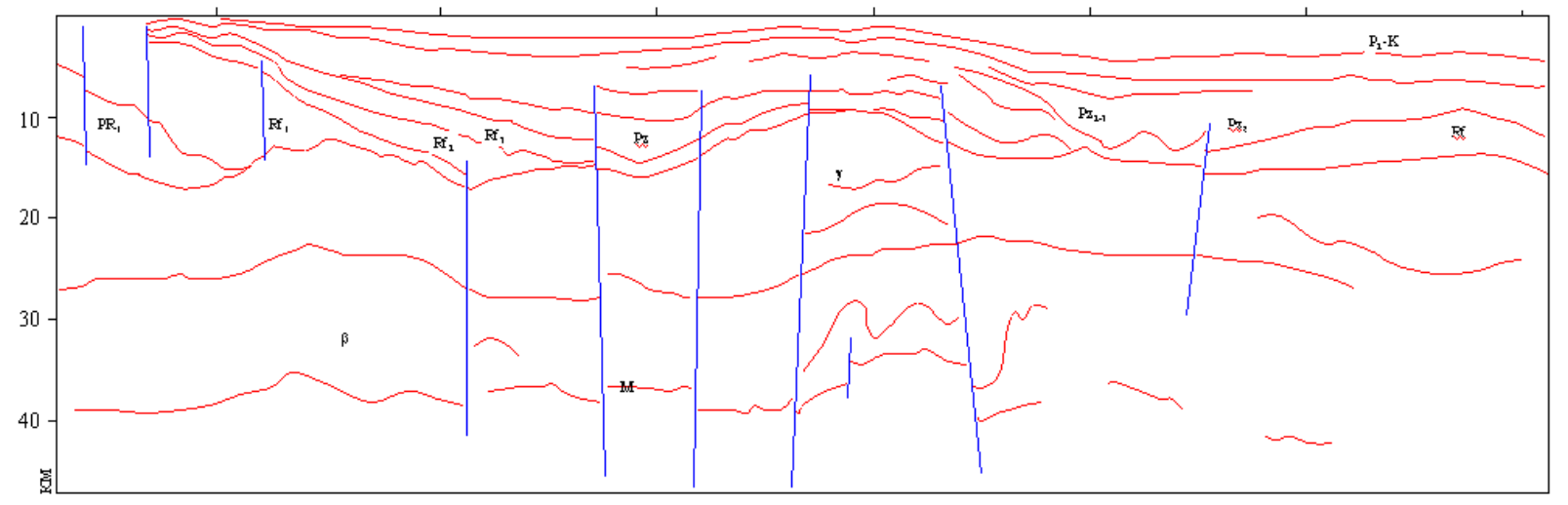

Figure 2: The structural tectonic cross-section along the AP-1 profile (according to Verba and Atakov, 1999). The stratification planes and faults reconstructed along the seismic wave cross-section (vertical lines) are shown

\section{RESULTS: PARAMETRIZATION OF THE WAVE MODEL IN SOLVING THE INVERSE PROBLEM OF THE POTENTIAL THEORY}

The gravity field in the $\Delta G_{B}$ Bouguer anomaly is considered as a result of the superposition of gravitational responses from various wavelengths. The regularity of its changes with depth is defined as determinated only in the area of the spatial (lateral) stationarity of the initial gravity field. The independent analysis of its components with various wavelengths is algorithmically implemented as a convolution procedure with the $h(\tau)$ transmission function defined at various length intervals. The $r_{A C F}$ radius of autocorrelation estimated in a sliding window is chosen as the spatial stationarity parameter of the profile signal presented here as $\Delta G_{B}$. These estimates are summarized in $[8,11]$ :

$r_{M g}=h(\tau)=\Delta G_{g}(x)$. 
The $r_{A C F}$ value may be converted into the depth of the anomaly-forming source since the autocorrelation radius is the parameter of the lateral extension of the gravity anomaly; formally, this possibility was justified by V. N. Strakhov and S. A. Serkerov (1991). In particular, the dependence of the autocorrelation radius on the depth of the source occurrence is determined by the geometry of the latter that is assessed by indirect criteria. For example, in the case of an isometric anomaly with a sufficiently extended extremum area, this refers to a spherical source. For an isometric anomaly with a narrow localized extremum area, one should speak of an endless material vertical stripe. In the case of expressed asymmetry, when the anomaly forms an area of a sharp spatial gradient on one of its sides, the model of semi-infinite horizontal material line is applied. Accordingly, there is a scatter in the assessment of the occurrence depth $h$ :

* for a spherical source:

$$
r_{\mathrm{ACF}}=\sqrt{8} h
$$

* for an endless material vertical stripe:

$$
r_{\mathrm{ACF}}=\pi h_{1} \frac{(m-1)^{2}}{4} / \ln \left(\frac{2^{m+1} m^{m}}{(m+1)^{m+1}}\right), m=h_{2} / h_{1}
$$

where $h_{1}$ and $h_{2}$ are the occurrence depths of the upper and lower edges of the body; and

* for the semi-infinite horizontal material line:

$$
r_{\mathrm{ACF}}=\pi h
$$

\section{DISCUSSION: TESTING THE WAVE ANALOGY}

The result of the depth recalculations with the use of relations (1) - (4) is shown in Fig. 3 and has the form of a family of wave profiles that show the presence of synforms and antiforms in the cross-section, as well as the zones of vertical correlation. In the conditions when the above-mentioned recalculations of the $\Delta G_{B}$ gravity field into the structure of a family of internal impounded gravitational waves (the term of hydrodynamics) are performed based on the $h(\tau)$ transfer function defined in an interval of variable length, however, in terms of the $\Delta G_{B}$ field, which does not change during the recalculation, the family of the wave profiles has three main features:

- the relief, the characteristic sign, and the amplitude of the gradient areas monotonically change with the depth from 0 to $50 \mathrm{~km}$;

- in some areas, the wave profiles show the absence of any features of the geological structure, while the structure of the gravity field in these areas can be described as highly differentiated; and

- the areas of the vertical correlations traced in the family of wave profiles are more gentle than the faults reconstructed according to the seismic wave cross-section but have approximately the same incidence angle.

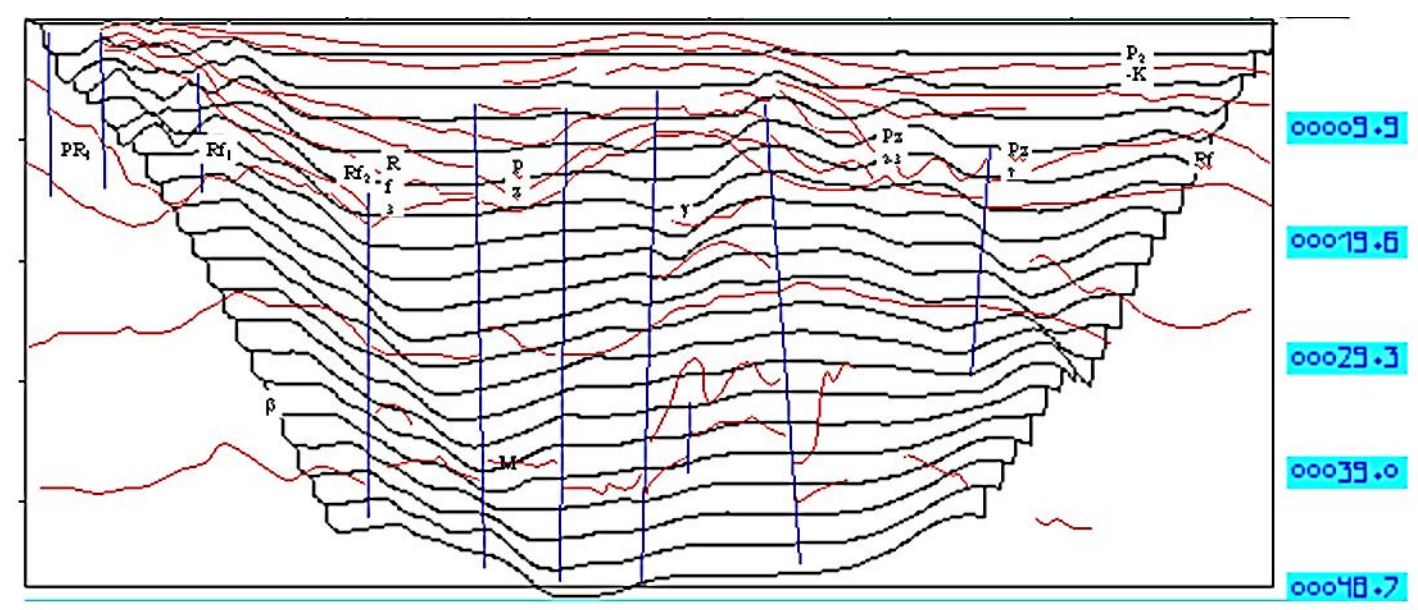

Figure 3: Recalculation of the gravity field in the Bouguer anomaly into the wave cross-section formed by the profiles of the internal impounded gravitational waves. The calculation was performed in a sliding window of variable dimensions with the same $\Delta G_{B}$ initial field processed in each of them. The red and blue curves that fill the plane of the cross-section repeat partially the black curves which are the result of gravity field recalculation.

All these features may be attributed to the shortcomings of the developed method. At the same time, even at this stage of calculations, one can note undoubted correlations between the obtained wave gravitational cross-section and the cross-section reconstructed from seismic data. In particular, the North-Murmansk embedded inlier and the adjacent West-Kola rift-induced depression in the South-Western part of the profile were shown. In the north-eastern part of the profile, one can see the Demidov aulacogen separated by a ledge from the adjacent Varanger graben. However, these correlations in the central part of the profile are only valid for the lower part of the cross-section and are quite conditional due to the smoothed nature of the profiles of the calculated internal gravitational waves. 
Improving this method of quantitative interpretation of the potential fields, the authors suggested that a narrow range of wavelengths in the structure of the initial gravity field should correspond to this interval of defining the $h(\tau)$ transfer function. In other words, now each stage of recalculation involves one of the components of the spatial signal $\Delta G_{B}$ obtained at the stage of preliminary frequency filtering, rather than the entire spatial signal $\Delta G_{B}$. The family of the calculated profiles of the internal impounded gravitational waves at various depths is shown in Fig. 4. The visual comparison of the structure of the seismic wave cross-section to the structure of the cross-section of the internal impounded gravitational waves calculated using the modified method shows high correlations across the entire plane of the cross-section. The suture zones that separate the regional structural units, including Karelian basement blocks, as well as Riphean, Caledonian, and Hercynian rift-induced depressions, are confidently expressed. One can see a sharp, almost abrupt change in the length of the internal impounded gravitational waves at the boundaries of the Paleozoic and Riphean formations, based on which the roof of the consolidated foundation is confidently expressed. The areas of lateral tracking disturbance in individual stratification planes combined in the seismic wave interpretation into subvertical faults are clearly distinguished as sharp gradient zones in the family of internal impounded gravitational waves, and, following the models of modern geotectonics, these zones become smoother as they move from the daylight surface to the roof of the upper mantle.

The obtained cross-section, like, admittedly, all geophysical cross-sections, requires additional interpretation, which determines its disrespect by geologists. In particular, in addition to the very unusual representation of the geological structures, discreteness is observed in the last cross-section the presence of empty space in the gap between individual waves, while the geological cross-section is on average a continuous medium. To compensate for this shortcoming, the authors recalculated each frequency component of the gravity field in the Bouguer anomaly to the depth levels corresponding to this component, which were specified by a separate profile of the internal impounded gravitational wave. This recalculation was supplemented by calculating the apparent density specified for the prismatic body with the depth limited by the overlaying and underlying wave profiles, and with the width limited by the positions of the measuring pickets. The traditional representation of the distribution of the apparent density in the cross-section in the form of an isoline map upon comparison to the seismic wave cross-section proved not indicative. Therefore, the authors suggested a method of flashing followed by the half-tone representation of the final cross-section (Fig. 5).

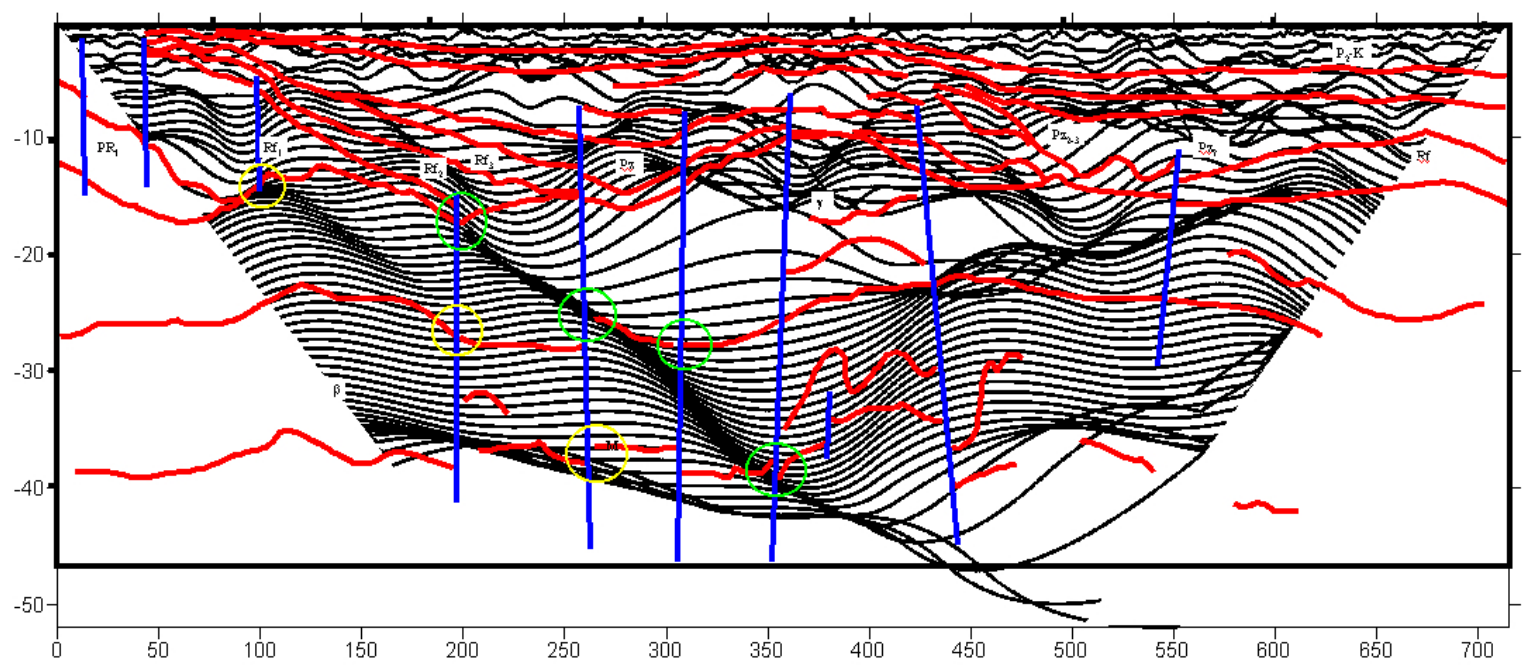

Figure 4: Recalculation of the gravity field in the Bouguer anomaly into the wave cross-section formed by the profiles of the internal impounded gravitational waves.

The calculation was performed in a sliding window of variable dimensions with one of the frequency components of the $\Delta G_{B}$ initial field processed in each of them. The vertical and horizontal axes were digitized in $\mathrm{km}$.

Technically, this method is widely used and implemented in specialized cartographic applications for analyzing the structure of isoline maps. Physically, this method considers the distribution of the density values as the distribution of the absolute heights of a certain conventional plane, in which the presence of appropriately related local forms may be detected by flashing at certain azimuths. The choice of the provisional height of the light source and the proper azimuth of the beam incidence leads to the formation of lighted and shaded areas that are visually merged into elongated or circadian structures. Mathematically, the light source is assumed to be homocentric, and the scattering of the rays that fall on the conventional surface satisfies the Lambert's cosine law. In this case, the brightness of each illuminated area of the 
conditional surface is proportional to the sine of the incidence angle.

The visual comparison of the structure of the seismic wave cross-section (the wide red lines) with the structure of the quasi-wave cross-section in Fig. 5 shows high correlations across the entire plane of the cross-section. The suture zones that separate the regional structural units, including Karelian basement blocks, as well as Riphean, Caledonian, and Hercynian rift-induced depressions, are confidently expressed. One can see a sharp, almost abrupt change in the length of waves at the boundaries of the Paleozoic and Riphean formations, based on which the roof of the consolidated foundation is confidently expressed. The areas of lateral tracking disturbance in individual stratification planes combined in the seismic wave interpretation into subvertical faults are clearly distinguished as sharp gradient zones in the reconstructed wave ensemble, and, following the models of modern geotectonics, these zones become smoother as they move from the daylight surface to the roof of the upper mantle.

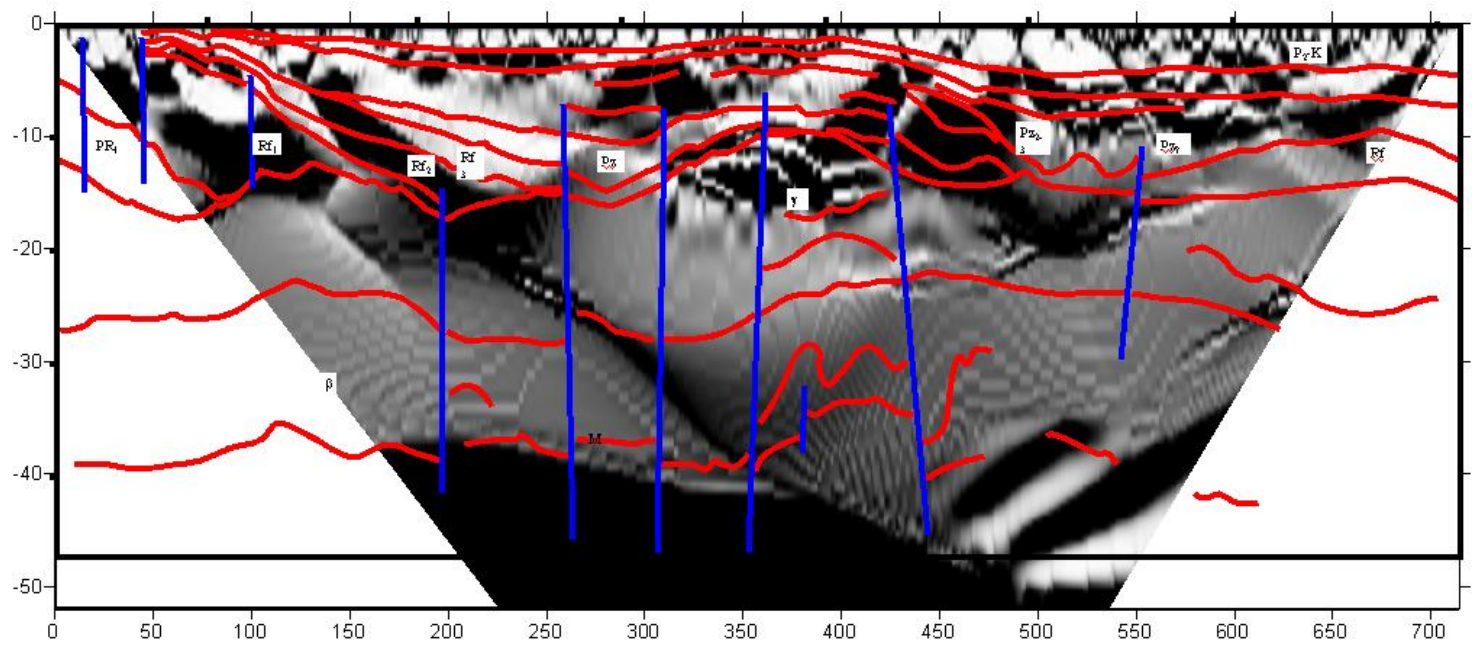

Figure 5: Reconstruction of the structural-tectonic cross-section along the AP-1 profile by calculating a system of internal impounded gravitational waves and calculating the apparent density at the level of each wave with the half-tone representation of its distribution in the cross-section plane.

The horizontal and vertical axes were digitized in $\mathrm{km}$.

\section{CONCLUSION}

By analogy with the wave structuring of non-equilibrium hydrodynamic media [12 - 14], a method for quasi-wave representation of a structural-geological cross-section has been developed based on the authors' recalculations of the gravity field in the Bouguer anomaly. The importance of this reconstruction method is that, firstly, its results are correlated with the seismic wave cross-sections, which fact sets this method apart from the classic methods of selection and analytical continuation, and, secondly, the resulting structural cross-sections have disjunctive and plicative dislocations of various ranks [15], which is essential for forecasting.

\section{REFERENCES}

1. G.P. Tafeev, K.P. Sokolov. Geologicheskaya interpretatsiya magnitnykh anomalii [Geological interpretation of magnetic anomalies]. Moscow. 1981. $327 \mathrm{p}$.

2. S.A. Serkerov. Spektralnyi analiz v gravirazvedke i magnitorazvedke [Spectral analysis in gravimetric and magnetic survey]. Moscow. 1991. 279 p.
3. A.S. Egorov, I.B. Movchan. Geologo-geofizicheskaya i geodinamicheskaya modeli litosfery po linii geotraversa Rubtsovsk - mys Nevelskogo [The geogeophysical and geodynamic models of the lithosphere along the Rubtsovsk - Cape Nevelsky geotraverse line]. Journal of Regional Geology and Metallogeny, pp. 110-118, 2000.

4. R.G. Berzin, A.K. Suleimanov, A.S. Egorov, I.B. Movchan. Glubinnoe stroenie zemnoi kory severa Vostochno-Evropeiskoi platformy i yuzhnoi chasti Baltiiskogo shchita vdol fragmenta opornogo profilya MOV-OGT "1-EV" (Kem-Lodeinoe pole-Pereslavl Zalesskii) [Deep structure of the Earth's crust in the Northern part of the East European platform and Southern part of the Baltic shield along the fragment of the MOV-OGT "1-EV" survey base line (Kem Lodeinoe Pole - Pereslavl Zalessky)]. Moscow: Abstracts of the XXXV tectonic meeting "Tectonics and Geophysics of the Lithosphere". 2002. pp. 230 - 235.

5. J. Turner. Gidrodinamika i ee prilozheniya [Hydrodynamics and its applications]. Moscow. 1982. pp. $135-140$.

6. D. Closson. Tectonics. Belgium: IntechOpen. 2011. 358 P.

https://doi.org/10.5772/567 
7. O.V. Petrov. Nelineinye yavleniya termogravitatsionnoi neustoichivosti i vnutrennie gravitatsionnye volny Zemli [Nonlinear phenomena of the thermogravitational instability and internal gravitational waves of the Earth]. Proceedings of the USSR Academy of Sciences, 326(3) pp. 506 - 509, 1992.

8. O.V. Petrov. The Earth's dissipative structures: fundamental wave properties of substance. Springer Geophysics (2019): 270. https://doi.org/10.1007/978-3-319-93614-7

9. J.W. Crowley, R.F. Katz, P. Huybers, C.H. Langmuir, S.H. Park. Glacial cycles drive variations in the production of oceanic crust. Science. 2015. Available at: www.sciencemag.org https://doi.org/10.1126/science. 1261508

10. D.T. Nelson, P.W. Jewell. Transgressive stratigraphic record and possible oscillations of late Pleistocene Lake Bonneville, Northern Hogup Mountains, Utah, U.S.A. Palaeo Journal, 432, pp. 58-67, 2015. https://doi.org/10.1016/j.palaeo.2015.04.028

11. R.M. Richardson, G. Zandt. Inverse problems in geophysics (GEOS 567). Tucson: University of Arizona, 2003, p. 241.

12. H. Benard. Les Tourbillons Cellulaires dans une Nappe Liquide Transportant de la Chaleur par Convection en Regime Permanent. Ann. Chem. Phys., 23, pp. 62-144, 1901.

13. D.L. Turcotte. Fractal and chaos in geology and geophysics. N/Y: Cambridge University Press, 1997, p. 398.

https://doi.org/10.1017/CBO9781139174695

14. H. Ramberg. Theoretical models of density stratification and diapirism in the Earth. J. Geophys. Res., 77, pp. 877-889, 1972. https://doi.org/10.1029/JB077i005p00877

15. A.S. Egorov, I.Yu. Vinokurov, A.N. Telegin. Scientific and methodical approaches to increase prospecting efficiency of the Russian Arctic Shelf state geological mapping. Journal of Mining Institute, vol. 233, pp. 447-458, 2018.

https://doi.org/10.31897/pmi.2018.5.447 